\title{
Are Sintered Silver Joints Ready for Use as Interconnect Material in Microelectronic Packaging?
}

\author{
KIM S. SIOW ${ }^{1,2,3}$ \\ 1.--Institute of Microengineering and Nanoelectronics (IMEN), Universiti Kebangsaan Malaysia, \\ 43600 Bangi, Selangor, Malaysia. 2.—e-mail: kimshyong@gmail.com. 3.—e-mail:kimsiow@ukm.my
}

Silver (Ag) has been under development for use as interconnect material for power electronics packaging since the late 1980s. Despite its long development history, high thermal and electrical conductivities, and lead-free composition, sintered Ag technology has limited market penetration. This review sets out to explore what is required to make this technology more viable. This review also covers the origin of sintered Ag, the different types and application methods of sintered Ag pastes and laminates, and the long-term reliability of sintered Ag joints. Sintered Ag pastes are classified according to whether pressure is required for sintering and further classified according to their filler sizes. This review discusses the main methods of applying $\mathrm{Ag}$ pastes/laminates as dieattach materials and the related processing conditions. The long-term reliability of sintered Ag joints depends on the density of the sintered joint, selection of metallization or plating schemes, types of substrates, substrate roughness, formulation of $\mathrm{Ag}$ pastes/laminates, joint configurations (i.e., joint thicknesses and die sizes), and testing conditions. This paper identifies four challenges that must be overcome for the proliferation of sintered Ag technology: changes in materials formulation, the successful navigation of the complex patent landscape, the availability of production and inspection equipment, and the health concerns of $\mathrm{Ag}$ nanoparticles. This paper is expected to be useful to materials suppliers and semiconductor companies that are considering this technology for their future packages.

Key words: Sintered silver joint, lead-free die-attach material, nano-silver, low temperature joining technique

\section{INTRODUCTION}

There is an ongoing search for reliable and environmentally friendly interconnect materials in the microelectronics packaging industry. Such interconnect material can be used as die-attach material or substrate-attach material. Substrate-attach material, also known as thermal-interface material, joins the substrate (also known as a direct copper bond, DCB) to the heat sink. The search for alternative materials is also strongly driven by the

(Received June 9, 2013; accepted December 23, 2013;

published online January 17, 2014) requirement for die-attach materials that do not contain lead $(\mathrm{Pb})$, as established by the Restriction of Hazardous Substances (ROHS) directives, to be reviewed in mid 2016 though the End-of-Life Vehicle directives specified an earlier deadline in 2014.

One possible candidate for satisfying these reliability and environmental criteria is the sintered silver (Ag) joint. Interest in sintered Ag joints can be attributed to their several advantages, such as a processing temperature similar to that of current high-lead solders, high thermal stability and conductivity, and superior mechanical and electrical properties compared with other lead-free alternatives in the market. ${ }^{1,2}$ This trend coincides with the proliferation of power semiconductor devices, such as silicon carbide and gallium nitride, which require 


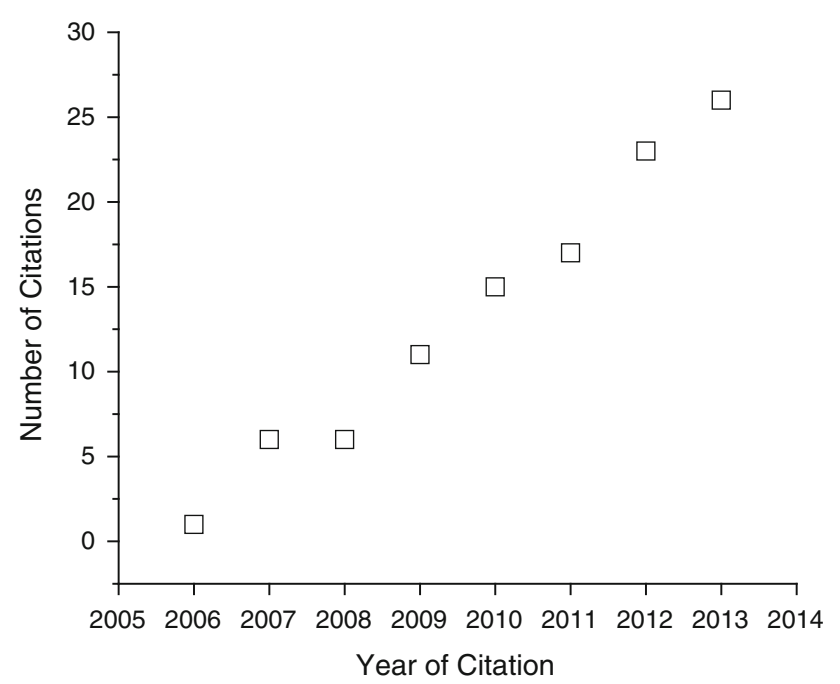

Fig. 1. Non-cumulative citations of one pioneering paper ${ }^{8}$ written by G.Q. Lu's group at Virginia Tech for the period of 2006-2013.

interconnect materials to operate at high switching speeds, high current densities, and junction temperatures of more than $200{ }^{\circ} \mathrm{C} .{ }^{3,4}$ In such a harsh environment, a sintered $\mathrm{Ag}$ joint is one of the few viable options because its high melting temperature implies a stable mechanical joint with a low homologous temperature $\left(\approx 0.3 T_{\mathrm{m}}\right){ }^{5}$ In addition, the high thermal conductivity of sintered $\mathrm{Ag}$ allows devices such as light-emitting diodes and laser diodes to operate at high luminance efficiencies compared with other epoxy-based die-attach materials. ${ }^{6,7}$ The increased interest in sintered Ag joints is reflected in the citation trend of one seminal paper concerning this technology (Fig. 1). ${ }^{8}$

At this stage of technology development, sintered Ag paste is commercially available, although its cost can be prohibitive-as much as 4-5 times more expensive than epoxy die-attach materials or solder materials. In terms of technology demonstration, sintered Ag joints can be formed fairly easily from these commercially available sintered $\mathrm{Ag}$ pastes in the laboratory or even in a high-volume manufacturing environment, as in the case of a power module produced by Semikron Elektronik. ${ }^{9,10}$ The main processing parameters, including preheating, sintering temperature, heating rate, sintering pressure, and sintering time, are well established and have been discussed elsewhere. ${ }^{5}$ In this review, we will re-examine the definition of a "sintered Ag joint" and examine the key issues preventing the proliferation of sintered Ag paste technology beyond the power electronics industry. Specifically, we will highlight the different types and application techniques of sintered $\mathrm{Ag}$ pastes or $\mathrm{Ag}$ laminates as well as the factors controlling their reliability and speculate regarding the future of this technology.

\section{WHAT IS A SINTERED AG JOINT?}

The history of sintered Ag joints, also known as the low-temperature joining technique, dates back to the late 1980 s. $^{11-13}$ In the early days, sintered $\mathrm{Ag}$ pastes used micron-sized Ag fillers to form silver joints, and they were sintered under pressures of 9-40 MPa at a temperature of $250{ }^{\circ} \mathrm{C} .{ }^{14}$ Hence, this technique was often called "pressure sintering." The invention of nano-Ag paste in the mid-2000s reduced the sintering pressure further to $1-5 \mathrm{MPa}$ while maintaining the sintering temperature in approximately the same range. ${ }^{15}$ This reduction in sintering pressure was made possible by the increase in effective surface area, which provides the driving force for sintering at lower pressure, associated with $\mathrm{Ag}$ nanoparticles. Regardless of the Ag fillers, these sintered Ag pastes differed from the sintered Ag pastes used to form the terminal electrodes of passive components for surface mounts in terms of materials formulation and sintering temperature (i.e., above $600{ }^{\circ} \mathrm{C}$ for the latter), though all of them share the same name-sintered Ag paste. ${ }^{16}$ This review will only consider sintered $\mathrm{Ag}$ pastes used as die- or substrate-attach materials.

Since the late 1980s, sintered Ag technology has evolved in terms of material compositions, manufacturing conditions, supply-chain management, processing conditions, technological performance, and customer requirements. Table I illustrates the major commercial entities involved in the value chain of sintered Ag technology today. This list is not exhaustive, as it only takes into account those entities that are actively promoting or publishing their work in exhibitions, conferences, and journals.

In addition to sintered $\mathrm{Ag}$ paste and $\mathrm{Ag}$ laminate, there are two other techniques that can produce sintered Ag joints, though they are not commonly known as "sintered Ag joints" in the literature. These two techniques and processing conditions are discussed below:

(a) Deposition techniques, such as electrolytic plating $^{17,18}$ or sputtering, ${ }^{19}$ are used to deposit silver layers on silicon dies ${ }^{17}$ or substrates ${ }^{18}$ or on both surfaces. ${ }^{19}$ These Ag-plated surfaces are pressed together at elevated bonding temperatures and pressures-240 ${ }^{\circ} \mathrm{C}(0 \mathrm{MPa}),{ }^{19} 260^{\circ} \mathrm{C}(7 \mathrm{MPa})^{18}$ or $350{ }^{\circ} \mathrm{C}(2 \mathrm{MPa}){ }^{17} \mathrm{~A}$ similar approach using the deposition of precipitated nanocrystalline $\mathrm{Ag}$ was patented by Siemens in the mid-1990s. ${ }^{20}$ The patent objective is "to provide the advantage of manufacturing a layer from a sinterable metal powder" and to form a die-attach joint using pressure sintering. ${ }^{20}$ In recent years, some researchers have renamed this deposition technique as the "silver direct bonding" technique. ${ }^{41}$

(b) Silver foil can also form reliable $\mathrm{Ag}$ joints at a bonding pressure of $7 \mathrm{MPa}$ and a temperature of $250^{21,22}$ or $260^{\circ} \mathrm{C} .^{23}$ In the literature, this joining 
Table I. Commercial entities from the semiconductor industry involved in the use of sintered Ag technology for die-attach or substrate-attach materials (in alphabetical order)

\begin{tabular}{|c|c|c|c|}
\hline $\begin{array}{l}\text { Sintered Ag paste } \\
\text { suppliers }\end{array}$ & Equipment suppliers & $\begin{array}{l}\text { Semiconductor } \\
\text { companies }\end{array}$ & End users \\
\hline $\begin{array}{l}\text { 1. Alent "Alpha"50 } \\
\text { 2. Applied Nanoparticle } \\
\text { Laboratory Inc. }^{107} \\
\text { 3. Dowa Electronics } \\
\text { 4. Henkel } 109 \\
\text { 5. Heraeus } \\
\text { 6. Namics } \\
\text { 6. N113 } \\
\text { 7. NBE Technologies } \\
\text { 8. Nihon Handa9 } \\
\text { 9. Nihon Superior } \\
\text { 115 } \\
\text { 10. Senju Metal } \\
116\end{array}$ & $\begin{array}{l}\text { Die-attach } \\
\begin{array}{l}\text { 1. Datacon }(B E S I) \\
\text { 2. Finetech Electronic }\end{array}{ }^{17,24} \\
\quad \text { Press } \\
\text { 1. Boschman Technologies } \\
\text { 2. Fico }{ }^{124} \\
\text { 3. Locatelli } \\
\text { 4. Schmidt Technology } \\
\text { 5. TOX Pressotechnik }\end{array}$ & 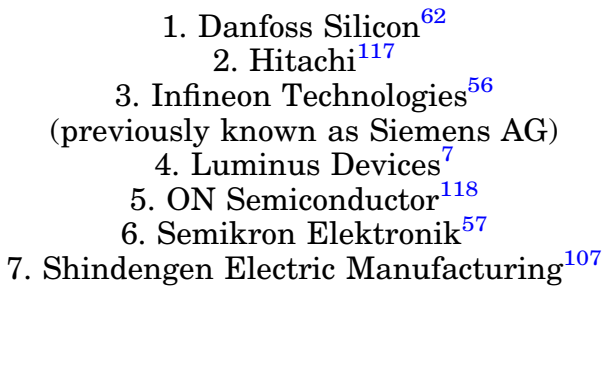 & $\begin{array}{l}\text { 1. Ford Motor }{ }^{119} \\
\text { 2. Magneti Marelli1 }{ }^{120} \\
\text { 3. Nissan Motor }{ }^{121} \\
\text { 4. Robert Bosch }\end{array}$ \\
\hline
\end{tabular}

process is commonly known as solid-state bonding ${ }^{23}$ or diffusion welding. ${ }^{22}$ Silver foil is differentiated from Ag laminate by its manufacturing process. Silver foil is rolled to a thickness of $10-20^{22}$ or $175 \mu \mathrm{m},{ }^{23}$ whereas silver laminate is essentially a Ag paste that has been printed on a carrier foil and dried to the pre-sintering stage before being used as a die- or substrate-attach material. ${ }^{15,24-26}$

Based on the foregoing discussion, the bonding conditions for $\mathrm{Ag}$ foil, $\mathrm{Ag}$ laminate and $\mathrm{Ag}$ plating appear to be similar to those used for sintered $\mathrm{Ag}$ paste. ${ }^{5}$ This similarity suggests a similar bonding mechanism that relies on the interdiffusion of atoms from joined substrates and possibly the sharing of electrons to ensure good bonding. ${ }^{18,23}$ Unless otherwise stated, a "sintered Ag joint" in this review refers to a joint produced using sintered Ag pastes.

Generally, the sintering mechanisms of $\mathrm{Ag}$ pastes depend on their formulation and Ag-particle sizes. In the case of $\mathrm{Ag}$ nanoparticles, the reduction of surface curvature or area and the related surface energies provide the driving force for the diffusion of atoms to neighboring particles during sintering. It has been reported that an $\mathrm{Ag}$ nanoparticle of $26 \mathrm{~nm}$ (in diameter) has a surface area of $23 \mathrm{~m}^{2} / \mathrm{g} .{ }^{27}$ In another study, regarding the neck size and particle size of Ag nanoparticles, the neck size was found to grow rapidly until it reached $50 \%$ of the particle size before slowing down. ${ }^{28}$ In the case of micron-sized Ag particles, other endothermically decomposable silver compounds, such as Ag-oxide or Ag-oxalate compounds, provide the bonding phases between adjacent silver particles when they reduce to reactive and pure $\mathrm{Ag}$ at temperatures above $\sim 200{ }^{\circ} \mathrm{C}$ (i.e., $220{ }^{\circ} \mathrm{C}$ for $\mathrm{Ag}$ oxide). The application of pressure aids in the diffusion of $\mathrm{Ag}$ atoms to densify the Ag joints during sintering. Further densification of Ag particles transforms the Ag surfaces into Ag grain boundaries in an exothermic process. On the other hand, the reduction of Ag oxide (and other endothermically decomposable silver compounds) to $\mathrm{Ag}$ and oxygen is an endothermic process. The evaporation of organic solvents from $\mathrm{Ag}$ paste is also an endo- thermic process that occurs at temperatures below $100{ }^{\circ} \mathrm{C}$, while the combustion of binders and passivating agents from Ag paste takes place between 200 and $280{ }^{\circ} \mathrm{C}$ in an exothermic reaction. These various thermal events can be isolated and observed in studies that utilize differential scanning calorimetry and thermogravimetric analysis, which are typically carried out as part of process development.

\section{TYPES OF SINTERED AG PASTES}

In general, sintered $\mathrm{Ag}$ pastes are classified as either "pressure" or "pressureless" Ag pastes based on the presence or absence of applied pressure during the sintering process. These "pressure" and "pressureless" $\mathrm{Ag}$ pastes are further classified according to the size of the Ag fillers* used to produce them. It is not unusual in the industry to apply pressure during the sintering of "pressureless" Ag paste to control the density and reliability of the sintered Ag joint. The application of pressure will deform and increase the contact surface area of neighboring Ag fillers to promote diffusion and densification. Hence, we should be mindful of this practice when discussing the various types of sintered Ag pastes.

\section{"Pressure" Micron-Ag Paste}

Micron-sized Ag fillers-typically with grain sizes of less than $15 \mu \mathrm{m}$-are mixed with an organic solvent, such as cyclohexanol, ${ }^{11,13}$ terpineol, ${ }^{29}$ ethylene glycol ether, ${ }^{29}$ or a cyclohexanol-methanol mixture, ${ }^{25}$ to control their viscosity for ease of printing or dispensing. This type of Ag paste will sinter under a pressure of $9 \mathrm{MPa}^{11,12}$ at a temperature of $180-250{ }^{\circ} \mathrm{C} .^{11}$ Alternatively, a higher pressure of $40 \mathrm{MPa}$ can be used to reduce the required sintering temperature and time ${ }^{14}$ and to control the densification of the sintered $\mathrm{Ag}$ joint. ${ }^{10}$

*Ag filler refers to either Ag particles or Ag flakes. A particle is approximately spherical with nearly identical lengths in all three dimensions, while flakes are layer-like structures with one dimension substantially smaller than the other two dimensions. 
Table II. Main additives used in nano-Ag paste ${ }^{5}$

\begin{tabular}{|c|c|c|}
\hline No & Component & Example \\
\hline 1 & $\begin{array}{l}\text { Dispersant/passivating layer/ } \\
\text { organic shell/capping agent }\end{array}$ & $\begin{array}{c}\text { Menhaden fish oils, poly(diallydimethyl ammonium chloride), } \\
\text { polyacrylic acid, polystyrene sulfonate, triethylene glycol, } \\
\text { methyloctylamine, dodecylamine, hexadecylamine, myristyl alcohol, } \\
\text { 1-dodecanol, 1-decanol stearic acid, oleic acid, palmitic acid, dodecanethiol }\end{array}$ \\
\hline 2 & Binder & Ethyl cellulose, polyvinyl alcohol, polyvinyl butyral, wax \\
\hline 3 & Solvents/thinner & $\begin{array}{l}\text { Isobornyl cyclohexanol, texanol, terpineol, butyl carbitol, } \\
\text { toluene, xylene, ethanol, phenol }\end{array}$ \\
\hline
\end{tabular}

\section{"Pressure" Nano-Ag Paste}

The introduction of nano-Ag reduces the required sintering pressure from 9-10 $\mathrm{MPa}$ to as low as $1 \mathrm{MPa}{ }^{15,30}$ Typical compositions of nano$\mathrm{Ag}$ pastes comprise passivated Ag nanoparticles with capping agents (e.g., amine-, carboxylic-acidor thiol-based compounds), binders and solvents (e.g., alcohol or toluene). (The interested reader can refer to this review ${ }^{5}$ for further discussion of the various types of capping agents, binders and solvents used in the formulation of sintered $\mathrm{Ag}$ pastes, and a summary of these material compositions is included in Table II for the reader's convenience.) The diameters of $\mathrm{Ag}$ nanoparticles are typically less than $100 \mathrm{~nm},{ }^{15}$ and the sintering temperature can be as high as $300^{\circ} \mathrm{C} .^{31}$ The reactivity of unpassivated $\mathrm{Ag}$ nanoparticles is well known; Ag nanoparticles will self-sinter without the application of any pressure if their capping agents are removed. However, a minimum pressure-the "threshold stress"-must be exceeded to form a reliable sintered $\mathrm{Ag}$ joint. It should be noted here that it is not necessary to completely remove the capping agent for bonding to be effective ${ }^{28,32,33}$ but leaving the organic residues in the sintered Ag joint will pose a risk to long-term reliability.

\section{"Pressureless" Micron-Ag Paste}

Since the early development of sintered Ag paste, there has been a desire to eliminate the pressure during the sintering stage because "pressureless" sintered Ag paste would represent a "drop-in" solution for the industry. "Pressureless" sintering allows this technology to be used on thin silicon chips, which may suffer from passivation cracking during pressure sintering.

One approach to fabricating a "pressureless" sintered Ag joint is to use "endothermically decomposable Ag" compounds, such as Ag oxide or $\mathrm{Ag}$ lactate, that will form silver particles when heated to approximately $230-350{ }^{\circ} \mathrm{C}$ to bridge the Ag fillers in the micron-Ag paste. ${ }^{34,35}$ As shown in the Ellingham diagram, silver oxides are ther- mally unstable, and they can easily reduce to metallic $\mathrm{Ag}$ at temperatures above $250{ }^{\circ} \mathrm{C}$ to allow sintering to occur. ${ }^{36}$ In the presence of oxygen, Ag atoms diffuse to neighboring $\mathrm{Ag}$ atoms at temperatures as low as $184{ }^{\circ} \mathrm{C}$ for the initiation of sintering. ${ }^{37}$ The typical sizes of these $\mathrm{Ag}$ fillers ranges from 0.1 to $10 \mu \mathrm{m}^{34,35}$ and up to a maximum of $18 \mu \mathrm{m} .{ }^{38}$

The application of pressure has a similar effect as increasing the weight percentage (wt\%) of the $\mathrm{Ag}$ fillers in the Ag paste because it increases the contact area between neighboring Ag fillers. Instead of applying pressure, it is possible to use a silver paste containing $92.6 \mathrm{wt} \% \mathrm{Ag}$ particles to produce sintered $\mathrm{Ag}$ joints during pressureless sintering. ${ }^{39}$ Instead of specifying the wt\% of silver, other researchers have specified the maximum carbon content of a silver paste to be less than $1 \mathrm{wt} \%$ to ensure that the silver fillers constituted a sufficient majority of the silver paste. ${ }^{38} \mathrm{~A}$ high weight percentage of Ag particles necessitates the use of solvents, such as butanol, propanol, and ethanol, to control the viscosity of the $\mathrm{Ag}$ paste. ${ }^{40} \mathrm{~A}$ solvent such as 2 ethyl-1,3 hexanediol is also included in the sintered Ag pastes to reduce the substrate oxides so that sintering can occur. ${ }^{41}$

\section{"Pressureless" Nano-Ag Paste}

Similar to "pressureless" micron-Ag pastes, the organic content of "pressureless" nano-Ag paste is reduced with respect to the typical composition, which contains $15 \mathrm{wt} \%$ of organic content in "pressure" nano-Ag paste, to less than 4 wt\%. ${ }^{42} \mathrm{~A}$ similar approach has been adopted by another research group to sinter Ag paste, although this group used a different metallo-organic $\mathrm{Ag}$ chemistry to initiate the pressureless sintering. ${ }^{43}$ Upon decomposition of the organic components, the high-density $\mathrm{Ag}$ nanoparticles are extremely reactive and sinter easily on a Ag-plated substrate $^{42}$ or even on bare copper without any application of pressure. ${ }^{43}$

However, it is still possible to produce die shear strengths of comparable values under similar 
pressureless sintering conditions using a paste with a lower weight percentage of $\mathrm{Ag}$ nanoparticles (i.e., $82 \mathrm{wt} \%$ ) if the die size is reduced to $1.1 \mathrm{~mm} \times$ $1.1 \mathrm{~mm}^{44}$ instead of the diameter of $6 \mathrm{~mm}$ applied in earlier efforts. ${ }^{42}$ This result can be attributed to the uniform thickness of printed $\mathrm{Ag}$ pastes, the small thermal stress-strains, the easy diffusion of oxygen, and the outgassing of solvent from the sintering sites in the case of small dies. ${ }^{5}$

\section{APPLICATION METHODS OF SINTERED AG PASTE}

The application methods for an Ag paste depend on the type of Ag paste. A search through the literature reveals four common methods:

1. Print on substrate $\rightarrow$ preheat $\rightarrow$ die attach $\rightarrow$ pressure sinter

2. Laminate or print on wafer $\rightarrow$ (preheat for printed silicon wafer) $\rightarrow$ saw silicon wafer $\rightarrow$ die attach $\rightarrow$ pressure sinter

3. Saw silicon wafer $\rightarrow$ laminate die $\rightarrow$ die attach $\rightarrow$ pressure sinter

4. Print/dispense on substrate $\rightarrow$ die attach $\rightarrow$ sinter

Methods 1-3 use "pressure" sintered Ag paste, while method 4 uses "pressureless" sintered Ag paste. A summary of the relationships among the various processing steps of methods $1-4$ is illustrated in Fig. 2, and the feasibility of these various methods is discussed in subsequent sections.

\section{Method One: Print on Substrate $\rightarrow$ Pre- heat $\rightarrow$ Die Attach $\rightarrow$ Pressure Sinter}

The printing of $\mathrm{Ag}$ paste onto a substrate is the most common approach for the application of paste that is reported in the literature. ${ }^{5,10}$ The printed $\mathrm{Ag}$ paste is preheated to approximately $50-100{ }^{\circ} \mathrm{C}^{34}$ or higher ${ }^{11}$ but below the sintering temperature of the
Ag paste. The objective of preheating the sintered Ag paste is to remove the solvent before the sintering step because rapid volatilization of solvent during the sintering profile tends to separate the bonding interfaces and produce voids within the sintered Ag joint. As mentioned earlier in "Types of Sintered Ag Pastes", solvent is initially added to Ag paste to achieve a suitable rheology for printing. After preheating the printed $\mathrm{Ag}$ paste, the next step involves attaching the silicon dies onto the Ag-printed substrate, and, at this point, the preheated Ag paste provides a temporary adhesion between the die and the substrate. After the dieattach step is completed, the sandwich structure (i.e., silicon die-sintered $\mathrm{Ag}$ paste-substrate) is "pressure sintered" at an elevated temperature of more than $200{ }^{\circ} \mathrm{C}$.

Pressure sintering is an unusual manufacturing step in the microelectronics packaging industry because pressure must be applied directly onto the silicon dies. Direct pressure can crack the passivation or interlayer dielectrics on the silicon dies, which is a reliability concern for long-term use. Special pressure-sintering equipment is needed for such work, and the press platen that comes in contact with the silicon dies is typically cushioned using high-temperature rubber. The need for such cushioning was acknowledged by the early developers, who used various terminologies, such as the deformable intermediate layer ${ }^{11}$ or elastically deformable materials, ${ }^{13}$ to describe this cushion. Suggested materials for this cushion are silicone rubber ${ }^{45}$ and fluoridated elastomer. ${ }^{13}$ An additional Teflon sheet is typically placed between the silicone rubber and the silicon die during pressure sintering to provide a smooth contact on the silicon die. Such a smooth surface can reduce any high local stresses, which can damage the silicon dies during pressure sintering. Pressure sintering can be performed on a single module or lead frame or on a " 5 in. $\times 7$ in."

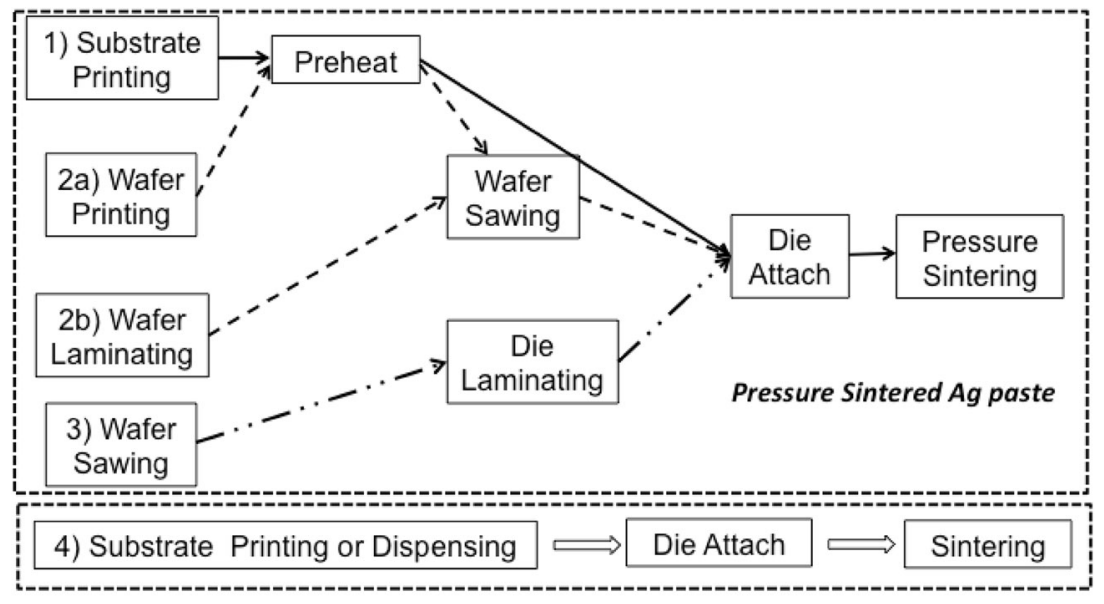

Pressureless Sintered Ag paste

Fig. 2. Various application methods for major classes of sintered Ag pastes. 
master card consisting of 120 silicon dies en masse. ${ }^{9}$ A pulsed current can also be used to form sintered Ag joints, ${ }^{46,47}$ but the pulsed-current method is less established in the industry than are the equipment and methods of pressure sintering.

\section{Method Two: Laminate or Print on Wafer $\rightarrow$ (Preheat the Printed Silicon Wafer) $\rightarrow$ Saw Silicon Wafer $\rightarrow$ Die Attach $\rightarrow$ Pressure Sinter}

In this method, one can first either laminate the $\mathrm{Ag}$ film or print the Ag paste onto the silicon wafer. $\mathrm{Ag}$ laminates are produced from either micron-sized $\mathrm{Ag}$ particles ${ }^{25}$ or Ag nanoparticles ${ }^{48}$ or a mixture of both micron-sized Ag and Ag nano-particles. ${ }^{24}$ This sintered Ag paste is printed onto a polymeric carrier before being dried in a profile similar to the preheating of printed $\mathrm{Ag}$ paste to produce the $\mathrm{Ag}$ laminate. These Ag laminates are printed and sold in sheets that are similar in size to the silicon wafers to be laminated or in rolls of continuously printed $\mathrm{Ag}$ paste. In the absence of a preheating stage, lamination of $\mathrm{Ag}$ films increases the productivity of this technology and provides better control of the dieattach thickness than does the Ag printing method. As mentioned in the section concerning the longterm reliability of $\mathrm{Ag}$ joints, the die-attach thickness is more crucial than the die size in determining the reliability of sintered Ag joints.

The lamination step is typically performed at $0.05-3 \mathrm{MPa}$ at temperatures between 50 and $175{ }^{\circ} \mathrm{C}$, while the sintering temperatures are similar to those described earlier $\left(175-400{ }^{\circ} \mathrm{C}\right)$ with pressures of less than $40 \mathrm{MPa}{ }^{48}$ Under these lamination conditions, $\mathrm{Ag}$ films adhere easily to silicon wafers. ${ }^{29}$ Although the mechanism of the lamination step has never been investigated in the literature, the foam structure of the $\mathrm{Ag}$ film and the surface diffusivity of the $\mathrm{Ag}$ atoms provide this temporary adhesion at elevated temperatures.

Instead of laminating, it is also possible to print the Ag paste directly onto the silicon wafer before preheating and sawing. ${ }^{49}$ This approach has not been widely reported in the literature, though it is widely known in the industry for use in waferbackside coating for epoxy die-attach materials.

After preheating the Ag paste or laminating the $\mathrm{Ag}$ laminate, the next processing step is wafer sawing. The purpose of wafer sawing is to separate individual dies from a large wafer so that the dies can be bonded onto individual chip carriers, also known as lead frames, which are typically made from copper. During wafer sawing, the $\mathrm{Ag}$-printed or Ag-laminated surface of the wafer is mounted on polymeric tape, which holds the wafer during sawing. Instead of adhering to the wafer, the preheated $\mathrm{Ag}$ paste may partially transfer onto the mounting tape, leaving an uneven layer of $\mathrm{Ag}$ paste for the subsequent die-attach and pressure-sintering steps. Therefore, the wafer-sawing process must be thoroughly characterized, because current process conditions and materials are tailored for wafers that are printed or laminated with epoxy die-attach material, which has a different adhesion mechanism and different material properties from $\mathrm{Ag}$ paste. The subsequent die-attach and pressure-sintering steps are similar to those in method one, described above.

\section{Method Three: Saw Wafer $\rightarrow$ Laminate Die $\rightarrow$ Die Attach $\rightarrow$ Pressure Sinter}

Instead of laminating the entire silicon wafer, the die-bonder can choose one sawn silicon die to laminate with the $\mathrm{Ag}$ film at elevated temperature. Then, the die-bonder attaches the Ag-laminated silicon die onto a heated lead frame or a DCB substrate. This method was proposed by Alent Plc and Datacon (BESI), and they named this approach the "Die Transfer Film" method. ${ }^{50}$ A separate pressuresintering step is required to sinter the attached silicon dies en masse to reduce the cycle time. A similar approach has also been applied at the Institute of Semiconductor Technology (Technical University of Braunschweig, TUB), though in that case, the die-attach and pressure-sintering steps are conducted simultaneously in a process known as "fineplacer pressure sintering". ${ }^{24,26}$ TUB has suggested a preheating temperature of $140{ }^{\circ} \mathrm{C}$ during the Ag lamination step and a sintering temperature of $250{ }^{\circ} \mathrm{C}$ with pressures ranging from 25 to $30 \mathrm{MPa}$ for the pressure-sintering step. ${ }^{24}$

\section{Method Four: Dispense/Print $\rightarrow$ Die Attach $\rightarrow$ Sinter}

This method is similar to the typical epoxy dieattach approach, which does not require any pressure for the sintering process. Unfortunately, "pressure" and "pressureless" Ag pastes have different degrees of densification, which result in significant differences in their mechanical, thermal, and electrical properties and concomitant differences in performance and reliability.

Thus far, the influence of the application methods of sintered pastes on the reliability of sintered Ag joints has not been thoroughly investigated because most published works are based on two methods: (1) printing on substrates, preheating, die attaching, and pressure sintering, and (2) dispensing on substrate, die attaching, and sintering. The $\mathrm{Ag}$ pastes that are available on the market are usually tailored for these two application methods, and further rheological modifications are required for the other application methods mentioned here.

\section{LONG-TERM RELIABILITY OF SINTERED AG JOINTS}

\section{High-Temperature Storage Tests}

The long-term stability of sintered Ag joints can be evaluated by measuring the die shear strength 
after annealing at elevated temperature for a specific duration. Such high-temperature studies are different from the sintering-time studies conducted during process development, which clearly demonstrate an increase in die shear strength for longer sintering times because of $\mathrm{Ag}$ densification. ${ }^{5}$ Besides the continuous densification of $\mathrm{Ag}$ joints, other processes are also taking place during such hightemperature annealing studies ${ }^{51-53}$ :

(a) The diffusion of $\mathrm{Ag}$ atoms from the sintered $\mathrm{Ag}$ paste into the silver-electroplated substrate or wafer-backside metallization strengthens the joint

(b) The oxidation or corrosion of the nickel barrier layers reduces the bonding between the sintered $\mathrm{Ag}$ and the nickel oxide

(c) The recrystallization and grain growth of the sintered Ag joint reduces the die shear strength

(d) The increase of pore sizes within the sintered Ag joint reduces the die shear strength

(e) The oxidation of the binders and capping agents in the pores of sintered $\mathrm{Ag}$ joints leads to swelling, delamination and cracking. ${ }^{51}$

As a consequence of these competing mechanisms, the die shear strength of a thermally aged sintered $\mathrm{Ag}$ joint may not be straightforward to model or predict. We expect the die shear strength to reduce over time because processes (b) to (e) should occur to a greater extent with a longer aging duration and/or a higher annealing temperature.

When one looks at Fig. 3, it is surprising to see that the densification of sintered Ag joints and stable metallization schemes were able to overcome some of the failure mechanisms described above. ${ }^{52-54}$ These observations are applicable to nano-Ag and micron$\mathrm{Ag}$ joints for temperatures ranging from 175 to $350{ }^{\circ} \mathrm{C}$ and up to $1,000 \mathrm{~h}$ of aging. According to Fig. 3, the sintered Ag joints either did not exhibit any reduction in die shear strength ${ }^{32}$ or experienced an increase in die shear strength for longer aging times. ${ }^{51,52}$ The reason for these results could be that with certain combinations of thickness, grain size, and purity in the metallization schemes, such as "Ni/ $\mathrm{Ag}$ " 51 or "Ni/Au", 52 it is possible to resist the failure related to the oxidation of the nickel barrier layer. The delamination and cracking of sintered Ag joints can be reduced by optimizing the sintering profile ${ }^{55}$ or increasing the thickness of the die-attach lay$\mathrm{er}^{53,54}$ to allow the organics to dissipate at a lower sintering temperature. Unfortunately, it is not always possible to change the die-attach thickness without compromising other elements of the mechanical or thermal performance of microelectronics packages.

\section{Thermal-Fatigue Properties}

Sintered Ag joints have better thermal-fatigue properties than $\mathrm{Pb}-\mathrm{Sn}$ and $\mathrm{Pb}$-free solder joints, and

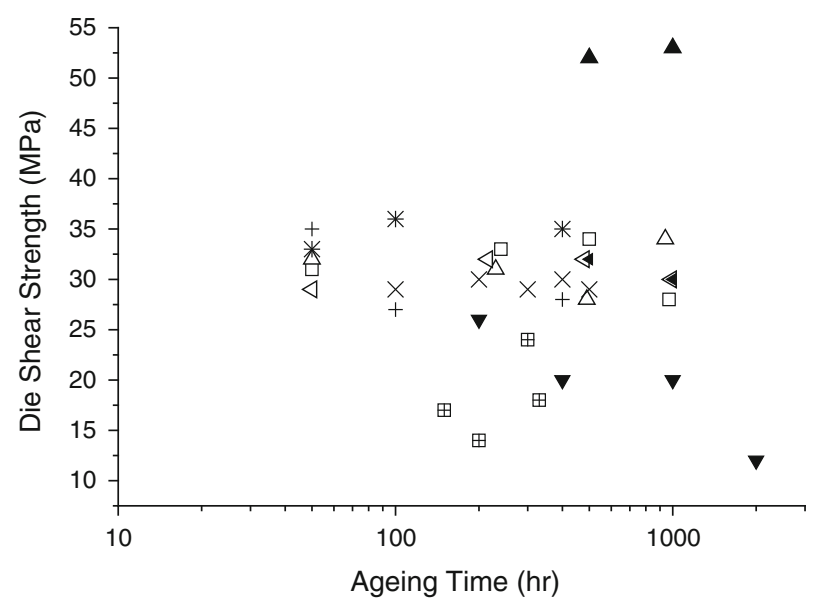

$\square$ nano-Ag $175^{\circ} \mathrm{C} \triangle$ nano-Ag $200^{\circ} \mathrm{C} \triangleleft$ nano-Ag $250^{\circ} \mathrm{C} \Delta$ nano-Ag $200^{\circ} \mathrm{C}$ $\checkmark$ nano-Ag $250^{\circ} \mathrm{C} \nabla$ nano-Ag+epoxy $250^{\circ} \mathrm{C}$ 田 micron-Ag $350^{\circ} \mathrm{C}$

+ micron-Ag $15 \mu \mathrm{m} 500^{\circ} \mathrm{C}$ * micron- $\mathrm{Ag} 110 \mu \mathrm{m} 500^{\circ} \mathrm{C} \times$ micron-Ag $350 \mu \mathrm{m} 500^{\circ} \mathrm{C}$

Fig. 3. Die shear strength of sintered $\mathrm{Ag}$ joints in high-temperature storage studies. ${ }^{26,32,51-54,84}$

these benefits have been demonstrated in powercycling tests ${ }^{9,10,56-61}$ and thermal-cycling tests. ${ }^{61-64}$ The following parameters have been used to evaluate the effects of fatigue stress on the integrity of sintered Ag joints: die shear strength, ${ }^{65-69}$ thermal and electrical resistance ${ }^{60,70}$ and "life cycle to failure" $\left(N_{f}\right)$. In the case of "life cycle to failure" $\left(N_{f}\right)$, the criterion for failure differs from one work to another; some researchers have used the loss of $20 \%$ of the die-bonded area the failure criterion, while others have used $10 \%$ of the die-bonded area ${ }^{62-64}$ Some researchers have defined a crack length equal to the thickness of the die-attach layer as the detection limit for observing crack lengths and failure criteria. ${ }^{71}$ Therefore, caution should be exercised when comparing results from different sources. The results of various thermal-cycling tests regarding the fatigue resistance (i.e., cycle to failure, $N_{\mathrm{f}}$ ) of sintered Ag joints are shown in Table III.

The larger change in temperature that accompanies a lower minimum temperature, $\mathrm{T}_{\min }$, can severely reduce the number of cycles to failure-by as much as $60 \%$, when comparing items (3) and (4) of Table III ${ }^{63}$ or $34 \%,{ }^{64}$ when comparing items (1) and (2) of Table III. A porous sintered Ag joint behaves like a viscoplastic material at high temperature. $^{63,72}$ At high temperature, sintered $\mathrm{Ag}$ joints undergo plastic deformation, resulting in crack formation, and these cracks propagate during thermal cycling. A larger temperature range imposes a higher strain on sintered Ag joints, which results in a shorter life cycle. The increase in the dwell time from 5.5 to $30 \mathrm{~min}$ also reduces the number of cycles to failure for sintered $\mathrm{Ag}$ joints by $24 \%{ }^{63}$ when comparing items (4) and (5) of Table III.

The failure mechanism is associated with dislocation pile-ups, which form microcavities at the grain boundaries of thermally cycled $\mathrm{Ag}$ joints. ${ }^{68}$ 
Table III. Cycles to failure $\left(N_{\mathrm{f}}\right)$ for sintered Ag joints in various thermal-cycling tests

\begin{tabular}{|c|c|c|c|c|c|c|c|}
\hline No & Types of Ag fillers & $\underset{\left({ }^{\circ} \mathbf{C}\right)}{T_{\min }}$ & $\underset{\left({ }^{\circ} \mathrm{C}\right)}{T_{\max }}$ & $\underset{\circ \mathbf{C})}{\operatorname{Delta} T}$ & $\begin{array}{l}\text { Dwell time } \\
\quad(\text { min })\end{array}$ & $\begin{array}{c}\text { Cycles to } \\
\text { failure }\left(N_{f}\right)\end{array}$ & Ref. \\
\hline 1 & Ag nanoparticles & -5 & 175 & 180 & $5 / 5^{\mathrm{a}}$ & 984 & 64 \\
\hline 2 & Ag nanoparticles & -55 & 175 & 230 & $5 / 5^{\mathrm{a}}$ & 646 & 64 \\
\hline 3 & Micron-sized Ag particles & -28 & 182 & 210 & $5 / 5$ & 556 & 63 \\
\hline 4 & Micron-sized Ag particles & -40 & 200 & 240 & $5.5 / 5.5$ & 221 & 63 \\
\hline 5 & Micron-sized Ag particles & -40 & 200 & 240 & $30 / 30$ & 168 & 63 \\
\hline 6 & $\begin{array}{c}\text { Electrodeposited Ag plating }(5 \times 5 \\
\times 0.035 \mathrm{~mm})\end{array}$ & -40 & 150 & 190 & $15 / 15$ & $>600$ & 17 \\
\hline
\end{tabular}

Delta $T$ refers to the range of testing temperature i.e. maximum temperature $\left(T_{\max }\right)-$ minimum temperature $\left(T_{\min }\right)$.Dwell time refers to time spent at $T_{\max }$ and $T_{\min } \cdot N_{\mathrm{f}}$ is based on Weibull statistics with bonded area of $80 \%$.Electrodeposited Ag plating was used as die attach materials to form a silver joint under pressure of $1.6 \mathrm{MPa}$ at a temperature of $350{ }^{\circ} \mathrm{C}$. ${ }^{\mathrm{a}}$ Based on cycle time of $1 \mathrm{~h}$, the dwell time is estimated to be $\sim 5$ min. ${ }^{64}$

There is a marked increase in pore size during thermal cycling; the percentage of pores in a sintered $\mathrm{Ag}$ joint has been found to increase from $12-13$ to $30 \%$ after 1,000 thermal cycles. ${ }^{69}$ The merging of these pores or cavities results in unstable crack growth and, therefore, the failure of the sintered Ag joints.

\section{Density of Sintered Ag Joints}

When one considers the similar conditions of items (2) and (4) of Table III, nano-Ag joints appear to have higher fatigue resistance than micron-Ag joints. Further analysis reveals that the die-attach thicknesses of these nano-Ag and micron-Ag joints were approximately $35-40 \mu \mathrm{m}$, while the die sizes used in the nano-Ag and micron-Ag joints were $14 \mathrm{~mm} \times 14 \mathrm{~mm}$ and $5.4 \mathrm{~mm} \times 3.4 \mathrm{~mm}$, respectively. ${ }^{63,64}$ A larger die is more susceptible to thermal fatigue failure than a smaller die because of the higher stress present in the larger die. In other words, the nano-Ag joints were subjected to more stressful conditions than the micron-Ag joints, but the former still performed better than the latter. One possible reason for this difference in performance is that a nano-Ag joint has a higher die shear strength than a micron-Ag joint, ${ }^{26,73}$ which leads to a higher fatigue resistance for the nano-Ag joint. This simple correlation may be flawed, however, as high-strength materials typically have low fracture toughness, which is a measure of the resistance to crack growth during cyclic loading. ${ }^{74}$

Another explanation for this observation in Table III is that the sintered nano-Ag joints had a higher density than the micron-Ag joints, although this postulate cannot be confirmed because the density for the micron $\mathrm{Ag}$ joints was not reported, ${ }^{63}$ while the density for the nano-Ag joints was only $80.4 \%{ }^{64}$ In a related study, Suganuma and coworkers $^{66}$ researched the influence of Ag-filler shapes on the thermal-fatigue resistance of sintered
Ag joints. Nanometer-thick Ag flakes produced sintered $\mathrm{Ag}$ joints that continued to densify and achieve higher die shear strengths during thermalcycling tests. This mechanism of increasing diffusion and density during thermal cycling was not observed for sintered $\mathrm{Ag}$ joints fabricated from $\mathrm{Ag}$ nanoparticles and $\mathrm{Ag}$ micron flakes. ${ }^{66}$ Therefore, it is important to consider the density of a sintered $\mathrm{Ag}$ joint instead of the shapes or sizes of the Ag fillers to understand the thermal-fatigue resistance of the joint.

When the density of a sintered Ag joint increases, its elastic modulus increases concomitantly. ${ }^{5}$ Generally, a material of high elastic modulus has less effective stress relief for the accommodation of plastic deformation than a low-density material. The inability to accommodate plastic deformation normally results in low fatigue resistance. How is it possible, then, for a sintered Ag joint of high elastic modulus to accommodate less plastic deformation and yet undergo more cycles to failure, as indicated by results presented earlier ${ }^{66}$ ? One possible explanation for this anomaly is that the shear strength increases more rapidly than the elastic modulus with increasing density. ${ }^{64}$ Consequently, there is a higher percentage of elastic strain (i.e., less plastic strain) in a high-density sintered Ag joint. This lack of plastic strain translates to slower progress toward failure, as per the Coffin-Manson Law. ${ }^{64}$ The current research trend favors sintered $\mathrm{Ag}$ joints of moderate density because of the need to balance the elastic modulus, die shear strength and fatigue strength. ${ }^{5}$ Because of the importance of the density and porosity of sintered $\mathrm{Ag}$ joints, some equations relating the porosity $(P)$ to the density $(\rho)$ and elastic modulus $(E)$ of sintered Ag joints are derived and presented here ${ }^{26}$ :

$$
\text { Porosity of sintered Ag }(P)=1-\frac{\rho_{\text {sintered Ag }}}{\rho_{\mathrm{Ag}}},
$$


Elastic modulus of sintered $\mathrm{Ag}(E)$

$$
=E_{\mathrm{Ag}} \frac{3(3-5 P)(1-P)}{9-P\left(9.5-5.5 v_{\mathrm{Ag}}\right)} .
$$

The density $\left(\rho_{\mathrm{Ag}}\right)$, elastic modulus $\left(E_{\mathrm{Ag}}\right)$ and Poisson's ratio $\left(v_{\mathrm{Ag}}\right)$ of bulk $\mathrm{Ag}$ are $10.494 \mathrm{~g} / \mathrm{cm}^{3}$, $80 \mathrm{GPa}, \mathrm{j}$ and 0.38 , respectively.

Closely related to density or porosity is the shape of the pores, which can also influence the stress distribution and grain growth of sintered $\mathrm{Ag}$ joints. Compared to the literature concerning nanocrystalline materials, ${ }^{75,76}$ similar studies that relate the density and porosity (including pore shapes) to the elastic modulus for sintered $\mathrm{Ag}$ joints are lacking. One common technique for characterizing these pores is to consider the ratio of the annular flaw size to the pore radius. ${ }^{77} \mathrm{~A}$ larger ratio suggests a longer and sharper crack, which promotes crack growth. The creation of a nanocrystalline material with an "open-pore" morphology and a relative density of $90 \%$ is the most effective method of controlling grain growth ${ }^{78}$ In addition, porosity can be controlled by applying post-annealing treatment at a temperature of $250{ }^{\circ} \mathrm{C}^{11}$ or, in certain cases, the tempering temperature can be higher than $380{ }^{\circ} \mathrm{C} .{ }^{53}$

\section{Interfacial Characteristics of Sintered Ag Joints}

In addition to the density of sintered Ag joints, the properties of the substrates also have a significant influence on their interfaces with Ag joints. Characteristics such as roughness and the coefficient of thermal expansion (CTE) play a crucial role in the fatigue properties of $\mathrm{Ag}$ joints. Sintered $\mathrm{Ag}$ pastes sinter readily on Ag surfaces or other noble metals, such as gold, palladium, or platinum. ${ }^{34}$ The plating of a noble alloy incurs additional costs for semiconductor companies because a certain minimum thickness is required to be effective as a sintering surface. Depending on the plating conditions, a Ag plating of $4 \mu \mathrm{m}$ in thickness would still be relatively porous, and the oxidation of the underlying copper would increase the CTE mismatch between the copper and the Ag plating, resulting in early thermal-fatigue failure. ${ }^{66}$ The formation of Kirkendall voids in the interfacial regions further exacerbate this thermal-fatigue failure. ${ }^{65,66}$

Among the various substrates on the market, bare copper has emerged as the most desirable surface for Ag joints. In one thermal-cycling study that used bare copper as a substrate, air-sintered Ag joints exhibited higher thermal and electrical resistance than $\mathrm{Ag}$ joints formed in a nitrogen atmosphere. ${ }^{70}$ These reduced properties of the air-sintered $\mathrm{Ag}$ joints were caused by the delamination of the copper oxide at the interface. It has also been reported elsewhere that $\mathrm{Ag}$ nanoparticles exhibit reduced adhesion on copper oxides compared to bare copper because of the reduced deformation and contact surface area on hard copper oxides compared to bare copper. $^{79}$ The literature normally suggests the application of a pre-cleaning step for the copper substrate using dilute acid before sintering to ensure good metallurgical bonding between the sintered Ag paste and the copper substrate. Such a pre-cleaning step is impractical to implement in high-volume production, however, because this approach necessitates an additional manufacturing step and the disposal of chemical waste. Hence, it is of utmost importance to formulate a sintered $\mathrm{Ag}$ paste that can function on a bare copper substrate in an inert atmosphere (typically nitrogen) to prevent copper oxidation. It has been reported that polyvinylpyrrolidone, when present in sufficient quantity in the nano-Ag paste, can provide the "in situ" cleaning of the faying copper during pressureless sintering, ${ }^{80}$ while the weight percentage and shape of the Ag fillers are likely to comply with the requirements discussed in "Pressureless" Micron-Ag Paste' and "Pressureless" Nano-Ag Paste'.

In addition to copper, aluminum and nickel platings are commonly found on the electrode and heatsink surfaces of power electronics packages. ${ }^{81} \mathrm{Ag}$ sintering on nickel surfaces has met with limited success to date, ${ }^{40}$ while an attempt to sinter nano$\mathrm{Ag}$ paste onto an aluminum surface has also proven unsuccessful. ${ }^{81,82}$ Similar to copper, aluminum and nickel have natural and tenacious oxides that are resistant to fluxing agents. An alternative strategy for sintering on aluminum is to use a mixture of endothermically decomposable Ag compounds-Ag oxide and $\mathrm{Ag}$ acetate- - to join to the aluminum oxide of the untreated aluminum surface. ${ }^{81}$ Another alternative approach to circumventing the lack of adhesion on non-noble metals is to incorporate an adhesive polymer into the $\mathrm{Ag}$ paste to provide the necessary adhesion strength, ${ }^{83}$ but Fig. 3 shows that hybrid polymer-Ag paste is not as reliable as a pure sintered Ag joint because epoxy degradation leads to cracking of the sintered $\mathrm{Ag}$ joints during high-temperature storage tests. ${ }^{84}$

The influence of substrate roughness on the fatigue resistance of sintered $\mathrm{Ag}$ joints has not been fully investigated nor published in the literature. Instead, most published works cite the relationship between the die shear strength of a sintered Ag joint and the related substrate roughness. Figure 4 shows that the die shear strength of a sintered $\mathrm{Ag}$ joint increases with decreasing average substrate roughness $\left(R_{\mathrm{a}}\right)$. ( $R_{\mathrm{a}}$ is the arithmetic average of the roughness profile.) When the sizes of the Ag nanoparticles are comparable to the substrate roughness, there will be an increase in the contact area between the Ag nanoparticles and the substrate. This increase in contact area will facilitate the diffusion process, thus promoting sintering at elevated temperatures. ${ }^{79}$ This conclusion is repeatable, whether the sintered Ag joints are made from printed nano-Ag paste ${ }^{85,86}$ or sputtered Ag. ${ }^{19}$ 


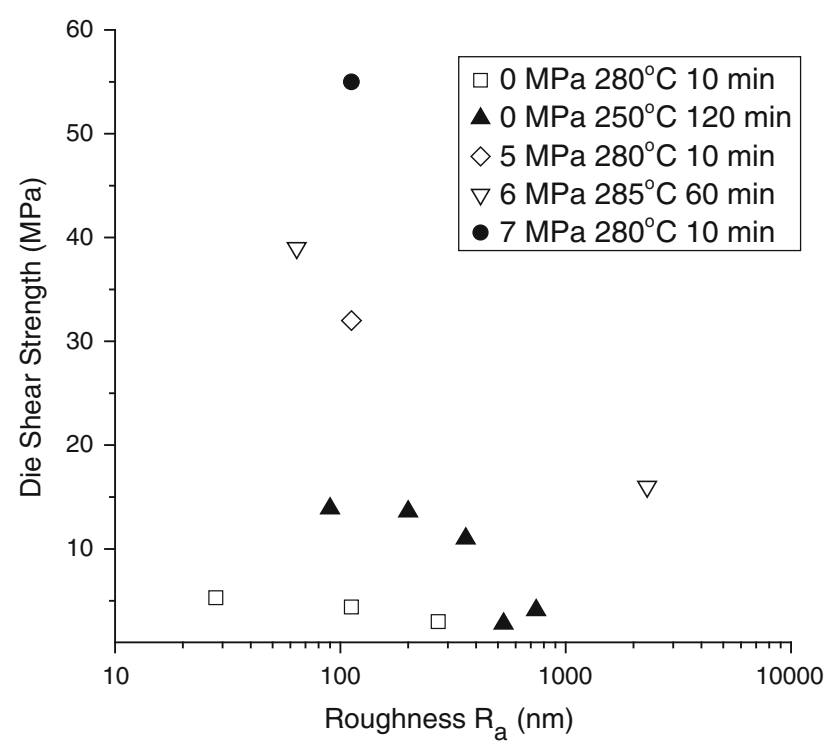

Fig. 4. Influence of substrate roughness $\left(R_{\mathrm{a}}\right)$ on the die shear strength of sintered $\mathrm{Ag}$ joints produced using nano- $\mathrm{Ag}$ paste ${ }^{85,86}$ or sputtered Ag. ${ }^{19}$ In these two studies, the nano-Ag pastes were procured from similar sources, and their filler sizes were less than $100 \mathrm{~nm}$. In the case of sputtered $\mathrm{Ag}$, the sintering was performed without any applied pressure.

In the case of a sputtered or deposited Ag layer, the surface roughness determines the initial contact areas between the bonding surfaces. Similar to the case of printed Ag paste, a smoother surface has a higher contact surface area for sintering. ${ }^{19}$ One research group has even attributed the root cause of their failure in thermal-cycle tests to their rough Ag plating. ${ }^{17}$ Depending on the joining surfaces, a maximum roughness of $1-1.5 \mu \mathrm{m}$ has been specified for the similar diffusion welding of a power thyristor onto a molybdenum substrate using $\mathrm{Ag}$ foil. ${ }^{22}$

As mentioned earlier in this review, we aim to draw lessons from the early successes of power electronics in the implementation of sintered $\mathrm{Ag}$ technology in other sectors of the microelectronics packaging industry. One major difference between the DCBs used in power electronics and the copper lead frames used by other sectors is the difference in the CTE mismatch between the DCBs and silicon dies and between the lead frames and the silicon dies. While investigating solid-state bonding using Ag foil and Ag-plated copper substrates, Lee's group proposed the maximum stress-free shear strain $(\gamma)$ as an indicator for this degree of mismatch, ${ }^{18,23}$ and this strain is given by Eq. 3:

$$
\gamma=\left(\alpha_{2}-\alpha_{1}\right)\left(T_{2}-T_{1}\right) \frac{L}{2 h},
$$

$\alpha_{2}$ and $\alpha_{1}$ are the CTE values of copper $\left(17 \mathrm{ppm} /{ }^{\circ} \mathrm{C}\right)$ or $\mathrm{Al}_{2} \mathrm{O}_{3} \quad\left(7 \mathrm{ppm} /{ }^{\circ} \mathrm{C}\right)$ and of the silicon die $\left(2.7 \mathrm{ppm} /{ }^{\circ} \mathrm{C}\right)$, respectively, $T_{2}$ and $T_{1}$ are the bonding/sintering temperature and room temperature, respectively, $L$ is the diagonal length of the silicon die, and $h$ is the thickness of the bonding (die-attach) layer.

This expression for the strain assumes the free contraction of both substrates during cool-down from bonding to room temperature. Based on this equation, there is approximately three times more stress for "copper-silicon" than for "DCB-silicon" joints. This additional stress must be accommodated by thicker die-attach layers or smaller die sizes. Because die sizes are usually defined by the circuit layout and performance, the die-attach thickness emerges as the most important design criterion for the implementation of this technology.

It has been reported that the die-attach thickness plays a more crucial role than the die size in thermal life-cycle studies of sintered Ag joints ${ }^{63}$ because different "stress-relief" mechanisms predominate at different die-attach thicknesses. ${ }^{71}$ According to that study, sintered Ag joints were found to be unsuitable for die-attach thicknesses of $75 \mu \mathrm{m}$ or more because of their increased propensity for crack growth instead of stress relaxation within the sintered Ag layer. ${ }^{71}$ This constraint on the die-attach thickness differs from the findings of an earlier report that recommends a thickness of more than $100 \mu \mathrm{m}$ to produce a fatigue-resistant joint between a DCB and a copper base plate. ${ }^{62}$ This difference can be attributed to the different bonding areas: an area of $5 \mathrm{~mm} \times 2.5 \mathrm{~mm}$ was used in the former study, ${ }^{71}$ while the latter study used a bonding area of $23 \mathrm{~mm} \times 18 \mathrm{~mm} .{ }^{62}$ Hence, caution must be exercised when adopting process parameters from different bonding interfaces in power electronics for copper lead frame products used in other sectors.

\section{Lifetime-Prediction Models of Sintered Ag Joints}

Compared to the literature regarding $\mathrm{Pb}-\mathrm{Sn}$ and $\mathrm{Pb}$-free solder joints, there are a limited number of publications that consider the lifetime-prediction models of sintered $\mathrm{Ag}$ joints. ${ }^{63,64,69,71,87,88}$ These lifetime-prediction models complement thermalfatigue lifetime studies, as mentioned earlier. Two of the more successful models that have been investigated for sintered Ag joints are the combined Navarro-de los Rios and small cracks interaction physical model ${ }^{69}$ and the modified Basquin model ${ }^{88}$ The combined Navarro-de los Rios and small cracks interaction physical model uses microstructures, including crack length, in the prediction model, ${ }^{69}$ while the Basquin model includes the influence of temperature on its fatigue-strength exponents and coefficients for the improvement of the model. ${ }^{88}$ These modifications generalize both models to be more representative of the measured data. It remains to be seen whether these models can be used to predict the lifetimes of sintered $\mathrm{Ag}$ joints produced elsewhere.

On the other hand, the generalized Garofalo steady-state creep model was found to be applicable only for the lifetime prediction of sintered Ag joints 
with a die-attach thickness of $25 \mu \mathrm{m}$, not for thicknesses of 50 or $75 \mu \mathrm{m} .{ }^{71}$ There are inherent limitations in this model, which is not capable of handling the evolving microstructures of these sintered $\mathrm{Ag}$ joints. Other lifetime-prediction models have also been borrowed from studies conducted using $\mathrm{Pb}-\mathrm{Sn}$ or $\mathrm{Pb}$-free solder joints. Hence, we should be mindful of the inherent differences between solder joints and sintered Ag joints; $\mathrm{Pb}-\mathrm{Sn}$ solder joints suffer from room-temperature aging, ${ }^{89}$ unlike thermally stable sintered Ag joints. ${ }^{5}$ Nevertheless, we are optimistic that there will be an increase in activities regarding lifetime-prediction models in the next few years because a typical sintered $\mathrm{Ag}$ joint exhibits more than 5,000 cycles to failure. Any techniques that can reduce the time required to accurately predict or evaluate a lifetime on this scale will garner interest among researchers and engineers.

\section{FUTURE OUTLOOK OF SINTERED AG JOINTS}

The value proposition of sintered $\mathrm{Ag}$ joints is clear; they are lead-free and reliable joints. The future outlook of this technology is bright if the microelectronics packaging industry can overcome the following four challenges:

\section{Formulation of Sintered Ag Paste}

The formulations of sintered Ag pastes are constantly changing to meet customer demands and requirements. Currently, the mechanical, electrical, and thermal properties of "pressureless" sintered Ag joints are not as reliable as those of "pressure" sintered Ag joints because of differences in the density and mechanical properties of the joints. Pressure sintering deforms and increases the contact surface area of neighboring $\mathrm{Ag}$ particles, thereby promoting diffusion and sintering. ${ }^{5}$

Instead of "pressureless" sintered Ag paste, some materials suppliers are marketing a "low-pressure" sintered Ag paste, for which the "threshold stress" of the Ag paste is as low as $0.07^{67}$ or $0.4 \mathrm{MPa}^{66}$ The "threshold stress" must be exceeded to achieve a significant increase in the density and strength of a sintered Ag joint. Such "low-pressure" formulations of Ag pastes typically exploit the shapes of $\mathrm{Ag}$ fillers ${ }^{66}$ with a mixture of micron-sized particles $(>1,000 \mathrm{~nm})$, sub-micron-sized particles (100$1,000 \mathrm{~nm})$ and nanoparticles $(<100 \mathrm{~nm}),{ }^{67,70}$ and other strategies that have been described earlier in "Pressureless" Micron-Ag Paste' and "Pressureless" Nano-Ag Paste'. Another advantage of using sub-micron- and micron-sized $\mathrm{Ag}$ fillers is their smaller surface areas compared to Ag nanoparticles, which translates into a lower volume of capping agent or dispersant in the Ag pastes. This lower volume of capping agent leads to fewer voids and higher reliability after joint formation. There is also the cost advantage of using sub-micron- and micron-sized $\mathrm{Ag}$ particles, which are typically available at only one-tenth of the cost of $\mathrm{Ag}$ nanoparticles. ${ }^{67}$

Another emerging trend in the formulation of sintered Ag pastes is the inclusion of silicon carbide (SiC), titania carbide (TiC), and hexagonal boron nitride $(\mathrm{h}-\mathrm{BN})^{54,90}$ or Ag-plated kovar or kovar particles $^{91}$ into sintered Ag paste to reduce the CTE of the sintered $\mathrm{Ag}$ joint and the thermal stress exerted by the substrates or silicon dies. This constant change in materials formulation has led to a very crowded patent landscape, which may pose a problem during implementation.

\section{Patent Landscape}

We have discussed different types of sintered $\mathrm{Ag}$ pastes earlier in "Types of Sintered Ag Pastes". The majority of these sintered Ag pastes were developed less than 5 years ago. Among the suppliers of sintered Ag paste that are listed in Table I, there are two start-ups that began at universities, namely, NBE Technologies (Virginia Polytechnic Institute and State University) and the Applied Nanoparticle Laboratory (Osaka City University). Later, Nihon Superior acquired the Applied Nanoparticle Laboratory to enter the sintered-Ag-paste market. One possible approach to solving multiple-claims issues regarding formulations of sintered $\mathrm{Ag}$ paste is to cross-license competitors' patent portfolios. Nihon Handa and Heraeus ${ }^{92}$ took this cross-licensing step in mid-2012.

In addition to materials suppliers, semiconductor companies such as Hitachi ${ }^{30}$ and Infineon Technologies $^{93}$ have also defined their own proprietary material compositions when claiming the processing conditions of their interconnect joints as part of their patent strategies. Even end-users, such as Toyota, have filed patents concerning the general composition of Ag pastes and sintering conditions. ${ }^{94}$ Such vertical integration demonstrates the patent holders' determination to use sintered Ag joints in their technology roadmap.

In the area of microelectronics package design, several semiconductor companies such as Infineon Technologies, ${ }^{95}$ Danfoss Silicon Power, ${ }^{96}$ Resnesas, ${ }^{97}$ and Semikron Elektronik ${ }^{98}$ have also defined sintered Ag joints as part of their package design or power-semiconductor components. Hence, it is prudent for any newcomers to file similar invention disclosures before using sintered $\mathrm{Ag}$ joints as part of their package designs.

\section{Availability of Production and Inspection Equipment}

As a consequence of continuous innovation in materials formulation, many semiconductor companies are facing a dilemma regarding whether to wait for the achievement of indistinguishable performance between "pressureless" and "pressure" sintered Ag pastes or to invest in pressure-sintering 
equipment. "Pressureless" sintered Ag paste does not require any capital investment because it requires similar processing procedures to epoxybased die attachment. In the case of "pressure" sintered Ag paste, many semiconductor companies, such as Infineon Technologies, ${ }^{99}$ Semikron Elektronik, ${ }^{100,101}$ and $\mathrm{ABB},{ }^{102}$ prefer to preserve their competitive advantages by designing their pressuresintering equipment in house. In the past 2 years, major equipment suppliers, such as those mentioned in Table I, have begun to develop generic pressure-sintering equipment for sintered Ag joints.

In terms of requirements for inspection equipment, the crack length, percentage of delamination, porosity, and density are the most critical parameters to assess during the process development of sintered Ag joints. To date, scanning acoustic microscopes (SAMs) have served as the industry workhorse for the monitoring of cracks and percentage of delamination. There are many challenges related to this inspection technique because of the length scale of these cracks; a crack is only detectable if it propagates sufficiently far from the edge of the silicon die. Destructive tests such as physical cross-sections must be conducted to monitor the porosity and density of sintered Ag joints. Any non-destructive methods that can reduce the development time will be eagerly welcomed by the microelectronics packaging industry.

\section{Health Concerns of Ag Nanoparticles}

The use of Ag nanoparticles in the microelectronics industry has raised concerns in the medical community. Much research has been written and reviewed concerning the possibility of nanoparticles penetrating through membranes, mucous layers, or skin to interfere with the chemical-biological systems of our bodies. ${ }^{103,104}$ The consensus is that metallic Ag is of relatively low toxicity; a non-lifethreatening bluish-grey discoloration of the skin, also known as argyria, is the only side effect when it is ingested or inhaled in high dosages. ${ }^{105}$ The antimicrobial properties of $\mathrm{Ag}$ nanoparticles have also been reported in the literature, ${ }^{104,106}$ although these results are often challenged because there are no standardized methods of testing these properties in vivo. ${ }^{105}$ In the case of microelectronics-grade nano-Ag paste, the synthesis and production of $\mathrm{Ag}$ nanoparticles is performed in solvent environments before they are formulated into a paste form. Hence, the risk of $\mathrm{Ag}$ nanoparticles being inhaled or ingested by humans is minimal. Once the nano-Ag paste is bonded in the die-/substrate-attach regions of electronics packages, the $\mathrm{Ag}$ joint is not dissimilar from bulk silver. These $\mathrm{Ag}$ joints are further encapsulated in plastics and similar materials. At the current stage of development, research is still ongoing to ascertain the full environmental impact of nano-Ag on its surroundings, including human beings, although current assessments indicate that this hazardous effect is minimal.

\section{CONCLUSIONS}

The general drive to operate at higher junction temperatures and higher luminance efficiencies and the impending deadline for conversion to $\mathrm{Pb}$-free products do not leave the industry with many alternatives. Sintered Ag paste is one promising candidate for this application. As discussed in this review, there are various methods of applying sintered Ag pastes, but most Ag pastes still requires an additional "pressure-sintering" step to form reliable sintered Ag joints. The pressure-sintering step requires innovation in either the formulation of $\mathrm{Ag}$ pastes or "pressure-sintering" equipment to overcome the risk of passivation cracks on the silicon dies. We did not review the various types of "pressure-sintering" equipment, as they were only launched early last year. We merely note that this equipment typically incorporates soft silicone rubber and an additional Teflon sheet to contact the silicon dies during pressure sintering. The current literature suggests that a sintered Ag joint has good thermal storage and thermal-fatigue properties if its density is sufficiently high to resist fatigue failure but low enough for stress relief. In addition to joint density, sintered Ag joints also depend on a suitable metallization or plating scheme, a compatible substrate and suitable substrate roughness to form reliable joints. Some design parameters, such as die sizes and bonding-layer thicknesses, require further investigation, along with the lifetime-prediction models for such sintered Ag joints. Nevertheless, the feasibility of using sintered Ag joints as interconnect material has been clearly demonstrated by many publications in this area, while reliability studies of sintered Ag joints are currently being conducted for various microelectronics-package designs. In conclusion, we are optimistic that the use of sintered Ag joints will proliferate beyond the power electronics industry into mainstream microelectronics packaging within the next few years.

\section{ACKNOWLEDGMENTS}

The author would like to thank his friends, colleagues, previous employers and materials and equipment suppliers who helped him to appreciate this sintered Ag technology. Special thanks go to Z. Chen (NTU) for valuable comments on this paper and to Y.M. Lam (NTU) and another former colleague who wishes to remain anonymous for carefully reviewing this paper.

\section{REFERENCES}

1. V.R. Manikam and K.Y. Cheong, IEEE Trans. Compon. Packag. Manuf. Technol. 1, 457 (2011).

2. K. Suganuma, S.J. Kim, and K.S. Kim, JOM 61, 64 (2009). 
3. G. Miller, Proceedings of the 6th International Conference on Integrated Power Electronics System (Nuremberg, 2010), p. 1 .

4. C. Buttay, D. Planson, B. Allard, D. Bergogne, P. Bevilacqua, C. Joubert, M. Lazar, C. Martin, H. Morel, D. Tournier, and C. Raynaud, Mater. Sci. Eng. B176, 283 (2011).

5. K.S. Siow, J. Alloys Compd. 514, 6 (2012).

6. G. Bai, Low-temperature sintering of nanoscale silver paste for semiconductor device interconnection (Ph.D. thesis, Virginia Polytechnic Institute and State University, 2005).

7. P. Panaccione, T. Wang, X. Chen, S. Luo, and G.Q. Lu, Proceedings of the 6th International Conference and Exhibition on Device Packaging (Arizona, 2010), p. 1.

8. J.G. Bai, Z.Z. Zhang, J.N. Calata, and G.Q. Lu, IEEE Trans. Compon. Packag. Technol. 29, 589 (2006).

9. U. Scheuermann, Microelectron. Reliab. 49, 1319 (2009).

10. C. Gobl and J. Faltenbacher, 6th International Conference on Integrated Power Electronics Systems (Nuremberg, 2010), p. 1.

11. H. Schwarzbauer, Method of securing electronic components to a substrate, US4810672, Siemens, USA (1989).

12. H. Schwarzbauer, Method and apparatus for fastening electronic components to substrates, US4903885, Siemens, USA (1990).

13. H. Schwarzbauer, Apparatus for fastening electronic components to substrates, US5058796, Siemens, USA (1991).

14. H. Schwarzbauer and R. Kuhnert, IEEE Trans. Ind. Appl. 27, 93 (1991).

15. G.Q. Lu, G. Lei, and J. Calata, Nanoscale Metal Paste for Interconnect and Method of Use, WO2009/094537A2 (Blacksburg: Virginia Tech Intellectual Properties, 2009).

16. Namics Corp, History, http://www.namics.co.jp/e/company/ enkaku.html. Accessed 22 May 2013.

17. V. Smet, M. Jamal, F. Waldron, F. Stam, A. Mathewson, and K.M. Razeeb, IEEE Trans. Compon. Packag. Manuf. Technol. 3, 533 (2013).

18. C.H. Sha and C.C. Lee, IEEE Trans. Compon. Packag. Manuf. Technol. 2, 194 (2012).

19. M. Kuramoto, T. Kunimune, S. Ogawa, M. Niwa, K.S. Kim, and K. Suganuma, IEEE Trans. Compon. Packag. Manuf. Technol. 2, 548 (2012).

20. H. Schwarzbauer, Pressure sintering method for fastening electronic components on a substrate, US5893511, Siemens, USA (1999).

21. J. Wang and C.C. Lee, IEEE Trans. Compon. Packag. Manuf. Technol. 33, 10 (2010).

22. H. Schwarzbauer, Method and apparatus for fastening semiconductor components to substrates US4903886, Siemens, USA (1990).

23. C.H. Sha and C.C. Lee, IEEE Trans. Compon. Packag. Manuf. Technol. 1, 1983 (2011).

24. J. Kahler, N. Heuck, A. Stranz, A. Waag, and E. Peiner, IEEE Trans. Compon. Packag. Manuf. Technol. 2, 199 (2012).

25. W. Baumgartner and J. Fellinger, Method of fastening electronic components to a substrate using a film, US4856185, Siemens, USA (1989).

26. J. Kahler, N. Heuck, G. Palm, A. Stranz, A. Waag, and E. Peiner, Electronics System Integration Technology Conference, ESTC 2010 Proceedings (Berlin, 2010), p. 1.

27. Z. Wei, M. Zhou, H. Qiao, L. Zhu, H. Yang, and T. Xia, J. Nanomater. 968058, 1 (2009).

28. A. Hu, J.Y. Guo, H. Alarifi, G. Patane, Y. Zhou, G. Compagnini, and C.X. Xu, Appl. Phys. Lett. 97, 1531171 (2010).

29. H. Schwarzbauer, Heat conducting adhesive joint with an adhesive-filled porous heat conductor, US6823915B2, Siemens, USA (2004).

30. M. Tobita and Y. Yasuda, Interconnect material and interconnect formation method, US2009/0180914A1, Hitachi, USA (2009).

31. H. Hozoji, T. Morita and H. Sasaki, Method for mounting an electronic part on a substrate using a liquid containing metal particles, US7393771B2, Hitachi, USA (2008).

32. T. Morita, E. Ide, Y. Yasuda, A. Hirose, and K. Kobayashi, Jpn. J. Appl. Phys. 47, 6615 (2008).
33. S. Wang, H. Ji, M. Li, and C. Wang, Mater. Lett. 85, 61 (2012).

34. W. Schmitt, M. Schafer, and H. W. Hagedorn, Controlling the porosity of metal pastes for pressure free, low temperature sintering process, US2010/0051319A1, W.C. Heraeus, Germany (2010).

35. W. Schmitt, T. Dickel and K. Stenger, Process and paste for contacting metal surfaces, US2009/0134206A1, W.C. Heraeus, Germany (2009).

36. Y. Mei, G.Q. Lu, X. Chen, S. Luo, and D. Ibitayo, IEEE Trans. Device Mater. Reliab. 11, 316 (2011).

37. S.K. Sharma and J. Spitz, Thin Solid Films 65, 339 (1980).

38. K. Yamakawa and K. Mine, Pasty silver particle composition, process for producing solid silver, solid silver, joining method and process for producing printed wiring board, US7766218, Nihon Handa (2010).

39. M. Kuramoto, S. Ogawa, M. Niwa, K.S. Kim, and K. Suganuma, IEEE Trans. Compon. Packag. Manuf. Technol. 33, 801 (2010).

40. I. J. Rasiah, Electrically conductive thermal interface, US7083850B2, Honeywell Internationa, USA (2006).

41. T. Kunimune, M. Kuramoto, S. Ogawa, M. Nogi, and K. Suganuma, IEEE Trans. Compon. Packag. Manuf. Technol. 3, 363 (2013).

42. J. Yan, G. Zou, A. Wu, J. Ren, J. Yan, A. Hu, and Y. Zhou, Scripta Mater. 66, 582 (2012).

43. A. Oestreicher, T. Röhricha, J. Wildenb, M. Lerchc, A. Jakobd, and H. Langd, Appl. Surf. Sci. 265, 239 (2013).

44. T. Wang, X. Chen, G.Q. Lu, and G. Lei, J. Electron. Mater. 36, 1333 (2007).

45. Z. Zhang and G.Q. Lu, IEEE Trans. Electron. Packag. Manuf. 25, 279 (2002).

46. Y. Mei, Y. Cao, G. Chen, X. Li, G.Q. Lu, and X. Chen, IEEE Trans. Device Mater. Reliab. 13, 258 (2013).

47. I. Nikitin, Method of manufacturing a semiconductor device, US7754533, Infineon Tech (2010).

48. O. Khaselev, B. Singh, B. Mo, M. Marczi, and M. Boureghda, Sintering materials and attachment methods using same, US2012/0114927, Fry's Metal, USA (2012).

49. H. Schwarzbauer, Method for fastening a semiconductor body provided with at least one semiconductor componet to a substrate, US5169804, Siemens, USA (1992).

50. Alent Plc Alpha, Argomax ${ }^{\mathrm{TM}}$, http://alphadieattach.com/, Accessed 22 May 2013.

51. S. Egelkraut, L. Frey, M. Knoerr, and A. Schletz, Proceedings of the 12th Electronic Packaging Technology Conference (Singapore, 2010), p. 660.

52. R. Kisiel, Z. Szczepanski, P. Firek, J. Grochowski, M. Mysliwiec, and M. Guziewicz, Proceedings of the International Spring Semiconductor Electronic Technology $(\mathrm{Bad}$ Aussee, 2012), p. 144

53. N. Heuck, S. Mueller, G. Palm, A. Bakin, and A. Waag, iMAPS Proceedings of HiTEC 2010, (2010), p. 1.

54. N. Heuck, G. Palm, T. Sauerberg, A. Stranz, A. Waag, and A. Bakin, Mater. Sci. Forum 645-648, 741 (2010).

55. T. Wang, M. Zhao, X. Chen, G.Q. Lu, K. Ngo, and S. Luo, J. Electron. Mater. 41, 2543 (2012).

56. R. Amro, J. Lutz, J. Rudzki, R. Sittig, and M. Thoben, Proceedings of the 18th International Symposium on Power Semiconductor Devices and ICs (ISPD'06), (Naples, 2006), p. 1.

57. T. Stockmeier, Proceedings of the International Symposium on Power Semiconductor Devices and ICs (Orlando, 2008), p. 12.

58. R. Amro, J. Lutz, J. Rudzki, M. Thoben, and A. Lindemann, Proceedings of the European Conference on the Power Electronics Application 2005 (Dresden, 2005), p. 1.

59. J. Steger, 1st International Electric Drives Production Conference 2011, EDPC-2011 Proceedings (Nuremberg, 2011), p. 60.

60. N. Pluschke and P. Beckedahl, IEEE International Symposium on Industrial Electronics (Hangzhou, 2012), p. 420.

61. U. Scheuermann, Conference Proceedings - IEEE Applied Power Electronics Conference and Exposition - APEC (Washington DC, 2009), p. 472. 
62. R. Eisele, J. Rudzki, and M. Kock, International Conference for Power Electronics, Intelligent Motion, Power Quality (Nuremberg, Curran Associates, 2007), p. 60.

63. T. Herboth, C. Fruh, M. Gunther, and J. Wilde, 13th International Thermal, Mechanical Multi-Physics Simulation Experiment in Microelectronic Microsystem (Cascais, 2012), p. 1.

64. M. Knoerr, S. Kraft, and A. Schletz, Proceedings of the 12th Electronic Packaging Technology Conference (Singapore, 2010), p. 56.

65. S. Sakamoto, S. Nagao, and K. Suganuma, J Mater. Sci. (2013). doi:10.1007/S10854-013-1138-X.

66. S. Sakamoto, T. Sugahara, and K. Suganuma, J. Mater. Sci. 24, 1332 (2013).

67. K. Suganuma, S. Sakamoto, N. Kagami, D. Wakuda, K.S. Kim, and M. Nogi, Microelectron. Reliab. (2011). doi: 10.1016/j.microrel.2011.07.088.

68. J.G. Bai and G.Q. Lu, IEEE Trans. Device Mater. Reliab. 6, 436 (2006).

69. G.C. Dong, X. Chen, and G. Q. Lu, 11th IEEE Intersociety Conference on Thermal and Thermomechanical Phenomena in Electronic System (Orlando, 2008), p. 793.

70. H. Ogura, M. Maruyama, R. Matsubayashi, T. Ogawa, S. Nakamura, T. Komatsu, H. Nagasawa, A. Ichimura, and S. Isoda, J. Electron. Mater. 39, 1233 (2010).

71. Y. Mei, G. Chen, X. Li, G.Q. Lu, and X. Chen, Solder. Surf. Mt. Technol. 25, 107 (2013).

72. D. Yu, X. Chen, G. Chen, G. Lu, and Z. Wang, Mater. Des. 30, 4574 (2009).

73. M. Knoerr and A. Schletz, Proceedings of the 7th International Conference on Integrated Power Systems IEEE (2010), p. 1.

74. R.W. Hertzberg, Deformation and Fracture Mechanics of Engineering Materials (New York: Wiley, 1996), p. 786.

75. K.S. Siow, A.A.O. Tay, and P. Oruganti, Mater. Sci. Technol. 20,285 (2004).

76. S.C. Tjong and H. Chen, Mater. Sci. Eng. R 45, 1 (2004).

77. V. Krstic, U. Erb, and G. Palumbo, Scripta Metall. et Mater. 29, 1501 (1993).

78. J.R. Groza, Nanostructured Materials: Processing, Properties and Potential Applications, ed. C.C. Koch (Norwich: Noyes, 2002), p. 115.

79. S. Joo and D.F. Baldwin, Nanotechnology 21, 055204 (2010).

80. P. Peng, A. Hu, H. Hong, A.P. Gerlich, B. Zhao, and N.Y. Zhou, J. Mater. Chem. 22, 12997 (2012).

81. Y. Yasuda, S. Terada, T. Morita, and H. Kawaji, Jpn. J. Appl. Phys. 51, 025001 (2012).

82. E. Ide, S. Angata, A. Hirose, and K.F. Kobayashi, Mater. Sci. Forum 512, 383 (2006).

83. T. Kunimune, M. Kuramoto, S. Ogawa, M. Niwa, M. Nogi, and K. Suganuma, IEEE Trans. Compon. Packag. Manuf. Technol. 2, 909 (2012).

84. F. Lang, H. Nakagawa, M. Aoyagi, H. Ohashi, and H. Yamaguchi, J. Mater. Sci. 21, 917 (2010).

85. A. Masson, C. Buttay, H. Morel, C. Raynaud, S. Hascoet, and L. Gremillard, Proceedings of the 14th European Conference on Power Electronic Application (Birmingham, 2011), p. 1.

86. L.A. Navarro, X. Perpina, M. Vellvehi, and X. Jorda, Ingenieria Mecanica Technologia Y Dessarrollo 4, 97 (2012).

87. R. Mrossko, H. Oppermann, B. Wunderle, and B. Michel, Proceedings of the NSTI Nanotechnology Conference and Expo, NSTI-Nanotech 2011 (Boston, 2011), p. 149.

88. X. Li, X. Chen and G.Q. Lu, Proceedings of the 13th International Conference Electronic Packaging Technology High Density Packaging (Guilin, 2012), p. 1209.

89. H. Ma and J.C. Suhling, J. Mater. Sci. 44, 1141 (2009).

90. N. Heuck, A. Langer, A. Stranz, G. Palm, R. Sittig, A. Bakin, and A. Waag, IEEE Trans. Compon. Packag. Manuf. Technol. 1,1846 (2011).

91. M. Kuramoto, S. Ogawa, M. Niwa, K.S. Kim, and K. Suganuma, IEEE Trans. Compon. Packag. Manuf. Technol. 1, 653 (2011).
92. Heraeus, Cross-licensing agreement on novel sinter technology signed, Bodo's Power System, (May 2012).

93. K. Guth and I. Nikitin, Module including a sintered joint bonding a semiconductor chip to a copper surface, US8253233, Infineon Tech, USA (2012).

94. T. Shibata, Y. Ishikawa, and T. Ichiyanagi, Bonding method, US7770781, Toyota Jidosha (2010).

95. R. Bayerer, Method of fabricating a high temperature compatible power semiconductor module, US2011/0070695, Infineon Tech, USA. (2011).

96. R. Eisele and M. Kock, Method for the low pressure sintering of electronic units to heat sinks, US8118211, Danfoss Silicon Power, USA(2012).

97. Y. Yato, T. Nakajo and H. Oka, Semiconductor device and manufacturing method of the same, US2009/0189264A1, Renesas Technology, USA (2009).

98. C. Goebl, P. Beckedahl, and H. Heilbronner, Power semiconductor component with metal contact layer and production method thereof, US8110925, Semikron Elektronik (2012).

99. R. Speckels, K. Guth, and H. Hartung, Apparatus and methods for producing semiconductor modules, US7851334, Infineon Tech. (2010).

100. G. Palm, Method for securing electronic components to a substrate, US2005/0247760A1, Semikron Elektronik (2005).

101. C. Gobl,Apparatus and clocked method for pressure-sintered bonding, US2007/0131353A1, Semikron Elektronik (2007).

102. W. Knapp, Method for mounting electronic components on substrates, US6935556B2, ABB Research, USA (2005).

103. S.W.P. Wijnhoven, W.J.G.M. Peijnenburg, C.A. Herbets, W.I. Hagens, A.G. Oomen, E.H.W. Heugens, B. Roszek, J. Bisschops, I. Gosens, D. Van de Meent, S. Dekkers, W.H De Jong, M. Van Zijverden, A.J.A.M. Sips, and R.E. Geertsma, Nanotoxicology 3, 109 (2009).

104. C. Voelker, M. Oetken, and J. Oehlmann, The Biological Effects and Possible Modes of Action of Nanosilver (New York: Springer, 2013)

105. S.F. Hansen and A. Baun, Nat. Nanotech. 7, 409 (2012),

106. R. de Lima, A.B. Seabra, and N. Durán, J. Appl. Toxicol. 32,867 (2012).

107. M. Maruyama, R. Matsubayashi, H. Iwakuro, S. Isoda, and T. Komatsu, Appl. Phys. A 93, 467 (2008)

108. Y. Hisaeda, K. Endoh, and S. Kurita, Joint Conference of "International Conference on Electronics Packaging" and "IMAPS All Asia Conference" (Tokyo, 2012), p. 1.

109. P. Gleeson, J. England, R. Kuder, J. Eckenrode, and J. Gutierrez, 3rd Advanced Technology Workshop and Tabletop Exhibition on Automotive Microelectronics and Packaging (Dearborn, Michigan, iMAPS, 2012), p. 1.

110. A. Dhakal, Transient liquid phase bonding and sintered silver paste for die-attach / substrate-attach in high power, high temperature applications, http://www.mrc.uidaho. edu/ atkinson/ECE591/Fa2011/Presentations/Dhakal. pdf. Accessed 22 May 2013.

111. S. Hascoet, C. Buttay, D. Planson, R. Chiriac, and A. Masson, Mater. Sci. Forum 740-742, 851 (2013).

112. W. Sabbah, R. Riva, S. Hascoet, C. Buttay, S. Azzopardi, E. Woirgard, D. A. Planson, and R. Meuret, Proceedings of the 7th International Conference on Integrated Power Systems (Nuremberg, 2012), p. 1.

113. Namics Corp, Low-temperature Sintered Conductive Pastes Using MO Technology http://www.namics.co.jp/ e/product/development01.html Accessed 22 May 2013.

114. NBE Tech, Products, Technology and Applications, http://www.nbetech.com/. Accessed 22 May 2013.

115. Nihon Superior, Nihon Superior to Exhibit Range of Innovative Products at the 2013 IPC APEX EXPO, http://news.thomasnet.com/companystory/Nihon-Superiorto-Exhibit-Range-of-Innovative-Products-at-the-2013-IPCAPEX-EXPO-30000371. Accessed 22 May 2013.

116. Senju Metal, Ag Nanopaste for Low Temperature Sintering, 
http://www.senju-m.co.jp/en/download/pdf/SMIC_ST2011_ EN_14.pdf. Accessed 22 May 2013.

117. Y. Akada, H. Tatsumi, T. Yamaguchi, A. Hirose, T. Morita, and E. Ide, Mater. Trans. 49, 1537 (2008).

118. K.S. Siow, 35th International Electronics Manufacturing Technology Conference (Ipoh, Malaysia, 2012), p. 1.

119. D. Berry, L. Jiang, K. Ngo, G. Lei, S. Luo, and G.Q. Lu, Proceedings of the PCIM 2013 (Nuremberg, 2013), p. 1.

120. R. Tiziani and X. Cao, Proceedings of the Advanced Packaging Conference Packaging Solution for the New Technology (Semicon Europa) (Dresden, Germany, 2012), p. 1.

121. T. Serizawa, CESA Congress Automotive Electronics Intl Conference and Exhibition (Paris, SIA, 2012), p. 1.
122. C. Fruh, M. Gunther, M. Rittner, A. Fix and M. Nowottnick, Proc. 2010 Electron. Syst. Integr. Tech. Conf. (Berlin, 2010), p. 1.

123. Alent Alpha and Boschman Technologies, Argomax ${ }^{\mathrm{TM}}$ and Boschman "S-Star Auto" Press, http://alphadieattach.com/ lead-frame.asp. Accessed 22 May 2013.

124. Alent Alpha and Fico Besi, Argomax ${ }^{\mathrm{TM}}$, Datacon Evo 2200, Fico sinter press, http://alphadieattach.com/module.asp. Accessed 22 May 2013.

125. G. Locatelli, Hydraulic Press, http://www.locatellime ccanica.com/hydraulic-presses. Accessed 22 May 2013.

126. J. Kahler, N. Heuck, A. Wagner, A. Stranz, E. Peiner, and A. Waag, IEEE Trans. Compon. Packag. Manuf. Technol. 2, 1587 (2012). 